\title{
Fear-avoidance beliefs and parental responses to pain in adolescents with chronic pain
}

\author{
Anna C Wilson $\mathrm{PhD}^{1}$, Amy S Lewandowski $\mathrm{PhD}^{2}$, Tonya M Palermo PhD ${ }^{2}$
}

AC Wilson, AS Lewandowski, TM Palermo. Fear-avoidance beliefs and parental responses to pain in adolescents with chronic pain. Pain Res Manage 2011;16(3):178-182.

BACKGROUND: The fear-avoidance model of chronic pain posits that fear of pain is associated with fear and avoidance of activity, which can lead to deconditioning and persistence of pain and disability. Despite being well supported in adults, little is known about the role of fear-avoidance beliefs regarding physical activity in children. Research has shown that parental protectiveness contributes to activity limitations in children; however, no studies have examined relationships between protectiveness, and fear and avoidance.

OBJECTIVES: To conduct a cross-sectional study to provide additional information regarding the reliability and validity of the Fear-Avoidance Beliefs Questionnaire physical activity subscale among adolescents with chronic pain; examine fear-avoidance beliefs and depressive symptoms as concurrent predictors of physical activity limitations; and test competing models using fear-avoidance beliefs as mediators and moderators of the association between parental protectiveness and activity limitations.

METHODS: Adolescents $(n=42) 11$ to 17 years of age with chronic pain completed questionnaires assessing pain intensity, fear-avoidance beliefs, depressive symptoms and physical activity limitations. Their parents completed questionnaires regarding protectiveness and adolescent activity limitations.

RESULTS: The Fear-Avoidance Beliefs Questionnaire physical activity subscale was useful for assessing fear-avoidance beliefs in the present population. In support of hypotheses, greater fear-avoidance beliefs were associated with greater activity limitations, above pain intensity and depressive symptoms. Support was found for fear-avoidance beliefs as mediators of the association between parental protectiveness and activity limitations. Tests of moderation were not significant.

CONCLUSIONS: Fear-avoidance beliefs may be an important target for interventions focused on decreasing activity limitations in youth with chronic pain. Future research should investigate these associations longitudinally.

Key Words: Chronic pain; Disability; Fear avoidance; Pediatric; Physical activity

$\mathrm{C}$ ognitions (eg, thoughts, beliefs and appraisals) play an important role in the experience of pain and pain-related disability (1). For instance, when children with chronic abdominal pain appraise pain as threatening or believe that they cannot reduce pain, it leads to poor pain-coping strategies, and increased pain symptoms and disability (2). When children and adolescents hold catastrophizing beliefs about pain, such as thinking that pain will continue to get worse or that their pain will never end, they are more likely to be disabled by their pain (3).

\section{FEAR-AVOIDANCE BELIEFS IN ADOLESCENTS}

Fear-avoidance beliefs regarding movement and physical activity are cognitions that link pain and physical activity (eg, "Physical activity makes my pain worse" or "I cannot do physical activities that make my pain worse"). These types of beliefs have been associated with increased pain intensity and disability in a broad range of adult chronic pain populations including adults with back pain, musculoskeletal pain and headache (4-6). The fear-avoidance model of chronic pain posits that

\section{Les croyances liées à la peur et à l'évitement et les réponses des parents à la douleur des adolescents ayant des douleurs chroniques} HISTORIQUE : Selon le modèle d'évitement et de peur en cas de douleur
chronique, la peur de la douleur s'associe à la peur et à l'évitement d'activités, qui
peuvent entraîner un déconditionnement et une persistance de la douleur et de
l'incapacité. Même si le rôle des croyances liées à l'évitement et à la peur à l'égard
de l'activité physique est bien étayé chez les adultes, on n'en sait pas grand-chose
chez les enfants. Les recherches démontrent que le caractère protecteur des
parents contribue à limiter les activités des enfants. Cependant, aucune étude n'a
porté sur les liens entre ce caractère protecteur, la peur et l'évitement.
OBJECTIFS : Mener une étude transversale pour fournir des renseignements
supplémentaires sur la fiabilité et la viabilité de la sous-échelle d'activité
physique du questionnaire sur les croyances liées à la peur et à l'évitement
chez des adolescents ayant des douleurs chroniques, examiner les croyances
liées à la peur et à l'évitement et les symptômes dépressifs à titre de
prédicteurs concomitants de limites à l'activité physique et vérifier des
modèles concurrents faisant appels aux croyances liées à la peur et à
l'évitement à titre de médiateurs et de modérateurs de l'association entre le
caractère protecteur des parents et les limites à l'activité.

MÉTHODOLOGIE : Des adolescents $(\mathrm{n}=42)$ de 11 à 17 ans ayant des douleurs chroniques ont rempli des questionnaires évaluant l'intensité de la douleur, les croyances liées à l'évitement et à la peur, les symptômes dépressifs et les limites d'activité physique. Leurs parents ont rempli des questionnaires sur le caractère protecteur et les limites à l'activité des adolescents.

RÉSULTATS : La sous-échelle d'activité physique du questionnaire sur les croyances liées à l'évitement et à la peur était utile pour évaluer les croyances liées à l'évitement et à la peur au sein de la population à l'étude. En appui avec les hypothèses, de plus fortes croyances liées à l'évitement et à la douleur s'associaient à des limites d'activité physique plus importantes, dépassant l'intensité de la douleur et les symptômes dépressifs. Les observations soutenaient le fait que les croyances liées à la peur et à l'évitement étaient des médiateurs de l'association entre le caractère protecteur des parents et les limites à l'activité. Les tests de modération n'étaient pas significatifs.

CONCLUSIONS : Les croyances liées à l'évitement et à la peur peuvent être une cible importante dans le cadre d'interventions visant à réduire les limites à l'activité chez les jeunes ayant des douleurs chroniques. Les futures recherches devraient évaluer ces associations sur le plan longitudinal.

fear of pain leads to fear and avoidance of physical activity, which, in turn, lead to deconditioning and the persistence of pain and disability (7). This model has been well supported in adults, but less is known about the role of fear-avoidance beliefs regarding physical activity in children and adolescents. Children and adolescents with chronic pain often withdraw from participation in sports, and have difficulty walking, running and performing routine physical activities $(8,9)$. Thus, one of the most prominent aspects of disability experienced by children and adolescents with chronic pain is limitations in physical activities; fearavoidance cognitions may contribute directly to these limitations.

There is evidence that fear of pain is associated with higher levels of disability in children with chronic pain, suggesting that the fearavoidance model may be applicable to children and adolescents (10); however, few studies have examined fear and avoidance of physical activity in particular. One study (11) of psychological treatment for longstanding chronic pain in adolescents showed levels of fear of physical activity that were similar to those of disabled adults with

${ }^{1}$ Child Development and Rehabilitation Center, Oregon Health $\mathcal{E}$ Science University, Portland, Oregon; ${ }^{2}$ Department of Anesthesiology and Pain

Medicine, University of Washington, Seattle, Washington, USA

Correspondence: Dr Anna C Wilson, Child Development and Rehabilitation Center, Oregon Health $\mathcal{E}$ Science University, 3181 Southwest

Sam Jackson Park Road, CDRC, Portland, Oregon 97239, USA. Telephone 503-494-0333, e-mail longann@ohsu.edu 
chronic pain, and demonstrated that treatment effectively reduced fear and improved physical functioning. Additionally, among healthy adolescents, fear of pain and physical activity have been shown to relate to pain frequency and the experience of somatic symptoms (12).

Few measures are available for assessing fear-avoidance beliefs regarding physical activity in children and adolescents. Previous studies $(11,13)$ have used measures initially developed for adults, including the Tampa Scale for Kinesiophobia (14), and the Fear-Avoidance Beliefs Questionnaire (FABQ [15]) to examine these types of beliefs in children and adolescents with chronic pain. Additionally, much of the research that has been conducted on the role of cognitions in pediatric chronic pain, including fear-avoidance cognitions, has involved school-age children, or mixed samples of children and adolescents. It may be important to examine fear-avoidance beliefs during adolescence because this developmental period is critical for the emergence of habits and cognitions related to physical activity participation that are likely to continue into adulthood $(16,17)$. For adolescents with chronic pain, these cognitions and habits may lead to an increased risk of disability in adulthood.

\section{PAIN-RELATED COGNITIONS IN THE FAMILY CONTEXT}

Adolescent cognitions regarding pain, including fear-avoidance beliefs, develop within the familial context. There is substantial evidence that parental responses to child and adolescent pain behaviours influence the experience of pain and related disability in children and adolescents $(18-21)$. Parental protectiveness refers to behaviours such as frequently attending to pain symptoms and/or allowing children to choose not to participate in regular activities (eg, getting out of doing chores or attending school). These types of parental behaviours are believed to inadvertently reinforce children's pain behaviours, and have been associated with the maintenance of pain symptoms over time and with greater health care use $(22,23)$.

A number of mechanisms have been proposed through which parental protectiveness or attending to pain might influence children's pain symptoms. First, parental attending to pain might increase children's somatic awareness, thereby prompting them to attend to bodily cues and making them more likely to notice pain sensations (24). Second, parental protectiveness might change or influence children's cognitions or emotions about their pain. For instance, if a parent expresses concern about pain symptoms or allows a child to stay home from school, a child might be more likely to appraise pain as threatening or dangerous (24). There is some evidence that children who are anxious or depressed might be more vulnerable to these parental behaviours $(18,20)$. Finally, if parents allow children to withdraw from regular activities (eg, school attendance), this may reinforce pain behaviours and increase avoidance, particularly for children who are less competent in these activities (22).

\section{AIMS AND HYPOTHESES}

Given the limited previous research pertaining to the measurement of fear-avoidance beliefs in adolescents, the first aim of the present cross-sectional study was to describe fear-avoidance beliefs, and provide additional information about the reliability and validity of the FABQ physical activity subscale (FABQ-PA [15]) in a sample of adolescents with chronic pain. It was hypothesized that the FABQ-PA would demonstrate adequate internal consistency and concurrent validity such that higher scores would be correlated with higher levels of physical activity limitations. The second aim was to examine fear-avoidance beliefs about physical activity as a concurrent predictor of physical activity limitations. Depressive symptoms were included in the analysis to ensure that any observed effects of fear-avoidance beliefs were not due to general negative cognitions, and also included pain intensity, which has been associated with activity limitations in previous research (9). It was hypothesized that, similar to findings in the adult chronic pain literature (15), fearavoidance beliefs would be associated with activity limitations above the effects of pain intensity. The third aim was to test fear-avoidance beliefs as potential mediators and moderators of parental protectiveness. It was hypothesized that higher levels of parental protectiveness would be associated with increased adolescent physical activity limitations. In the mediation model, parental protectiveness is hypothesized to be associated with increased physical activity limitations, and adolescent fearavoidance beliefs regarding physical activity are hypothesized to account for a significant proportion of this association, acting as one mechanism through which parental protectiveness influences activity limitations. In the moderation model, it is hypothesized that fear-avoidance beliefs will interact with parental protectiveness such that children who have higher fear-avoidance levels will be more vulnerable to parental protectiveness and, thus, more likely to have higher levels of physical activity limitations when parental protectiveness is high.

\section{METHODS}

\section{Participants}

The sample consisted of 42 adolescents ( 11 to 17 years of age) with chronic pain conditions and their parents. Adolescents were included in the sample if they were 11 to 17 years of age and had pain present for three months or more that was not due to an identified chronic disease. Patients were referred to the study from pain management, neurology and gastroenterology specialty care clinics. Of the eligible subjects who were approached to participate in the study, $74 \%$ of families agreed to participate and provided consent. The most common reason for active refusal to participate was lack of time or interest in participating in the research; however, the majority of refusals were passive (ie, not returning phone calls or unable to be reached by telephone). The age and sex of adolescents who refused to participate did not differ significantly from adolescents who participated.

The sample had a mean $( \pm$ SD) age of $14.90 \pm 2.11$ years and was $73.8 \%$ female. The ethnic distribution of the sample was $88.1 \%$ Caucasian, $7.1 \%$ Hispanic, 2.4\% Pacific Islander and 2.4\% other ethnicity. The majority of parents reported that they were married and living with their spouse $(79.1 \%)$, while the remainder reported their marital status as divorced (11.6\%), separated $(2.3 \%)$, remarried $(4.7 \%)$ or never married $(2.3 \%)$. The majority of participating parents were mothers $(86.0 \%)$, while $11.6 \%$ were fathers and one was a grandmother who had primary custody of the adolescent. Primary pain diagnoses included headache $(n=11)$, abdominal pain $(n=23)$ and musculoskeletal pain $(n=8)$. Annual family incomes ranged from less than $\$ 10,000$ to more than $\$ 100,000$, with the mean income ranging from $\$ 50,000$ to $\$ 69,000$.

\section{Procedures}

Approval for the conduct of research was granted by the institutional review board. Informed consent was obtained from parents, and adolescents gave assent to participate in the study. Data were obtained from questionnaires completed during a visit to the patient's home. Adolescents and their parents completed questionnaires, which included measures of demographics, pain characteristics, fear-avoidance beliefs, parental protectiveness and physical activity limitations. The parent- and child-report questionnaires were completed independently.

\section{Measures}

Sociodemographics: Parents completed a questionnaire assessing sociodemographic variables, and were asked to report on marital status, annual family income and their child's ethnicity.

Pain characteristics: Adolescents reported on their chronic pain characteristics using a pain questionnaire. They were asked to rate usual pain intensity in the past month using a 0 to 10 numerical rating scale. Adolescents also reported pain frequency via a single item assessing how often they experienced pain in the past three months. Response options ranged from 0 (not at all) to 6 (daily).

Depressive symptoms: Adolescents completed the 10-item major depressive disorder subscale of the Revised Child Anxiety and Depression Scale (25), which assesses depressive symptoms based on the criteria from the Diagnostic and Statistical Manual of Mental Disorders, 4th Edition. Responses ranged from 0 (never) to 3 (always), and were summed to obtain a depressive symptoms score. Higher scores indicated higher levels of depression. The Revised Child Anxiety and Depression Scale has demonstrated good reliability and validity in children and adolescents (25). 
TABLE 1

Descriptive statistics and correlations among study variables

\begin{tabular}{|c|c|c|c|c|c|c|}
\hline & \multirow{2}{*}{$\begin{array}{c}\text { Score, } \\
\text { mean } \pm \text { SD }\end{array}$} & \multicolumn{3}{|c|}{ Adolescent report } & \multicolumn{2}{|c|}{ Parent report } \\
\hline & & Pain intensity & Depressive symptoms & CALI child & Parental protectiveness & CALI parent \\
\hline \multicolumn{7}{|l|}{ Child report } \\
\hline Fear-avoidance beliefs & $11.52 \pm 5.43$ & 0.22 & 0.28 & $0.42^{\star *}$ & $0.47^{\star \star}$ & $0.44^{\star *}$ \\
\hline Depressive symptoms $^{\dagger}$ & $55.98 \pm 13.50$ & & & 0.23 & 0.11 & 0.24 \\
\hline CALI child & $19.86 \pm 6.19$ & & & & $0.29^{\star}$ & $0.51^{\star \star}$ \\
\hline \multicolumn{7}{|l|}{ Parent report } \\
\hline CALI parent & $21.05 \pm 6.09$ & & & & & \\
\hline
\end{tabular}

${ }^{\star} P<0.05 ;{ }^{\star *} P<0.01 ;{ }^{\dagger}$ Scores are $T$ scores. CALI Child Activity Limitations Interview

TABLE 2

Multiple regression models predicting physical activity limitations

\begin{tabular}{|c|c|c|c|c|}
\hline & \multicolumn{2}{|c|}{ CALI child report } & \multicolumn{2}{|c|}{ CALI parent report } \\
\hline & $\Delta \mathbf{R}^{2}$ & $\beta$ at final step & $\Delta \mathrm{R}^{2}$ & $\beta$ at final step \\
\hline Step 1 & $0.38^{\star \star \star}$ & & 0.08 & \\
\hline Household income & & -0.23 & & 0.09 \\
\hline Usual pain intensity & & $0.47^{\star \star \star}$ & & 0.23 \\
\hline Step 2 & 0 & & 0.02 & \\
\hline Depressive symptoms & & -0.03 & & 0.05 \\
\hline Step 3 & $0.16^{\star *}$ & & $0.17^{\star \star}$ & \\
\hline Fear-avoidance beliefs & & $0.42^{\star *}$ & & $0.43^{* *}$ \\
\hline Total $\mathrm{R}^{2}$ & $0.54^{\star \star \star}$ & & $0.27^{*}$ & \\
\hline
\end{tabular}

${ }^{*} P<0.05 ;{ }^{* *} P<0.01 ;{ }^{* * *} P<0.001$. CALI Child Activity Limitations Interview

Fear-avoidance beliefs: Adolescents completed the five-item FABQ-PA subscale to assess fear-avoidance beliefs regarding physical activity (15). The physical activity subscale of this questionnaire includes items that assess the degree to which a patient fears pain, or believes that physical activity will cause harm and worsen pain (eg, "Physical activity makes my pain worse"). Response items ranged from 0 (completely disagree) to 6 (completely agree), with higher scores indicating higher fear-avoidance beliefs. The FABQ also includes a subscale that assesses work-avoidance beliefs. This is scored separately from the FABQ-PA, and was not included in the current study because the majority of adolescents were not yet involved in regular work activities. Cronbach's alpha on the FABQ-PA reported in the validation sample was 0.77 (15).

Parental protectiveness: Parents reported on their own protectiveness behaviours using the 15-item protect subscale of the Adult Responses to Children's Symptoms questionnaire (26). Items included questions such as "When your child has pain, how often do you bring your child special treats or little gifts". Responses ranged from 0 (never) to 4 (always), and were averaged to obtain a protect score. Higher scores indicated higher levels of protectiveness. The Adult Responses to Children's Symptoms questionnaire has shown good reliability and validity $(23,26)$.

Physical activity limitations: Parents and adolescents reported on adolescent physical activity limitations due to pain using the retrospective version of the Child Activity Limitations Interview (CALI [9]). For the CALI, children and parents responded to an item-selection list of 21 activities (eg, running, gym, chores or doing things with friends) and chose the eight activities that were the most difficult or bothersome to the child due to recurring pain. The primary score was derived from the difficulty ratings of the eight most difficult activities, which were obtained using a five-point scale from 0 (not very difficult) to 4 (extremely difficult), with total scores ranging from 0 to 32 and higher scores indicating higher limitations. The CALI has shown good reliability and validity (9).

Analyses

All analyses were conducted using SPSS version 17.0 (IBM Corporation, USA). Descriptive statistics were calculated for all study variables.
Reliability scale alpha was calculated for the FABQ-PA. Bivariate correlations were used to examine FABQ-PA validity by testing associations between fear-avoidance beliefs and other study measures. Multiple linear regression models were used to examine the contribution of fear-avoidance beliefs to physical activity limitations. In step 1, usual pain intensity was controlled for, as was family income. Depressive symptoms were entered in step 2 and fear-avoidance beliefs in step 3 of the model. Moderation analyses predicting adolescent activity limitations were conducted using multiple linear regression as per Baron and Kenny (27). The moderation model tested the potential interaction between fear-avoidance and protectiveness as a predictor of physical activity limitations.

Continuous predictors were centred and multiplied to create the interaction term. Step 1 included parental protectiveness and fearavoidance beliefs, and step 2 included the interaction term. Bootstrapping procedures and the Sobel test were used to test indirect effects in mediation analysis (28). The mediation model included parental protectiveness as a direct predictor of physical activity limitations, testing fear-avoidance beliefs as a mediator.

\section{RESULTS}

Descriptive statistics and correlations with the FABQ-PA

Descriptive statistics and correlations among all study variables are shown in Table 1. Adolescents reported moderate levels of usual pain intensity, ranging from 2 to 10 on a 0 to 10 numerical rating scale (mean $6.57 \pm 1.74$ ). The majority of the sample $(72.1 \%)$ reported experiencing pain on a daily basis. Parents reported levels of protectiveness (mean $1.79 \pm 0.51$ ) that were higher than the scores reported in the validation sample (mean 1.36 \pm 0.63 ), and similar to those reported in a sample of parents of children with chronic headaches (29).

Adolescents reported moderate levels of fear-avoidance beliefs (mean 11.52 \pm 5.43 ). FABQ-PA scores were slightly lower than those reported in adult chronic low back pain samples, which have been reported to average approximately $14.0(30,31)$. The FABQ-PA subscale had slightly low internal consistency reliability, with a Cronbach's alpha of 0.69. Scores were normally distributed (skewness $=-0.43$ ). As hypothesized, the FABQ-PA subscale demonstrated concurrent validity, and was significantly positively correlated with parent and adolescent reports of physical activity limitations as measured by the CALI (Table 1). The FABQ-PA was also positively associated with parental protectiveness (Table 1). The FABQ-PA was not significantly associated with adolescent reports of usual pain intensity or depressive symptoms (Table 1). Additionally, the FABQ-PA was not associated with age, sex or family income in the present sample.

Contribution of fear-avoidance to physical activity limitations In regression analyses, usual pain intensity was a significant predictor of adolescent report of activity limitations. Additionally, as hypothesized, FABQ-PA scores contributed significantly to physical activity limitations above the effects of household income, usual pain intensity and depressive symptoms (Table 2 ). These effects were moderate and in the expected directions, such that children reporting greater fear and avoidance experienced greater activity limitations as measured by 


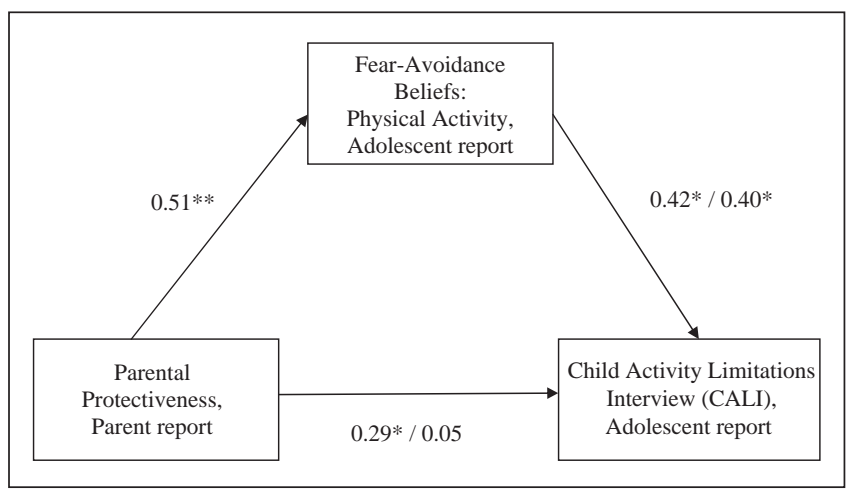

Figure 1) Fear-avoidance mediates the association between parental protectiveness and adolescent physical activity limitations. Data presented as beta values. $* P<0.05 ; * * P<0.01$

the CALI. Similar magnitudes of the effects of fear and avoidance were observed across both parent and child reports on the CALI.

Fear and avoidance as mediators or moderators of the association between parental protectiveness and activity limitations

Support was found for fear and avoidance as mediators of the association between parental protectiveness and child report of activity limitations as measured by the CALI (Figure 1). The initial relationship between protectiveness and CALI scores $(\beta=0.29, P=0.05)$ was nonsignificant $(\beta=0.05, P=0.75)$ after accounting for FABQ-PA scores $(\beta=0.42$, $P=0.02$ ). This indirect effect was significant (Sobel test, $z=1.97$, $\mathrm{P}=0.05$ ). A similar pattern was observed with parent report of CALI scores, although the test for the indirect effect approached significance (Sobel test, $z=1.91, \mathrm{P}=0.06$ ).

In multiple regression analyses for testing moderation, no support was found for fear-avoidance beliefs interacting with parental protectiveness to predict either parent $(\beta=0.14, \mathrm{P}=0.71)$ or child $(\beta=0.47, \mathrm{P}=0.22)$ report of physical activity limitations as measured by the CALI. These results are presented in Table 3. The interaction terms predicting both child and parent reports of activity limitations were nonsignificant.

\section{DISCUSSION}

The FABQ-PA subscale demonstrated good validity in the present sample because adolescent responses were associated with parent and child reports on the CALI in the expected directions, with greater fearavoidance related to higher levels of physical activity limitations. In bivariate correlations, fear and avoidance was not associated with pain intensity, suggesting that pain and pain-related fear and avoidance may be independent factors that contribute to the development of disability among individuals with chronic pain (4). It should be noted that the reliability of the FABQ-PA subscale was somewhat low in the present sample ( $\alpha=0.69 ; \alpha>0.70$ has been established as acceptable). Because the measure was originally developed for use among adults with chronic back pain, it may be more reliable in samples consisting of only children or adolescents with back pain, as opposed to the mixed chronic pain sample that was used in the current study. Fear and avoidance of physical activity might be most relevant in pain conditions affecting the musculoskeletal system (7) and may not be as salient in other pain conditions (eg, abdominal pain). It is also possible that these types of measures need to be revised to achieve greater reliability when used with children and adolescents.

In the present sample of adolescents with chronic pain, higher levels of fear-avoidance beliefs regarding physical activity were associated with greater physical activity limitations, after controlling for family income, usual pain intensity and depressive symptoms. This finding highlights the important role that adolescent cognitions about physical activity may play in chronic pain outcomes. Similar to findings in the adult chronic pain literature (32), our results indicate that fear-avoidance beliefs contribute to activity limitations with the same or greater magnitude than pain intensity. This is also consistent with previous child
TABLE 3

Multiple regression models testing the interaction between fear-avoidance beliefs and parental protectiveness

\begin{tabular}{|c|c|c|c|c|c|c|}
\hline & \multicolumn{3}{|c|}{ CALI child report } & \multicolumn{3}{|c|}{ CALI parent report } \\
\hline & $\Delta \mathbf{R}^{2}$ & $\begin{array}{l}\beta \text { at } \\
\text { entry }\end{array}$ & $\begin{array}{l}\beta \text { at final } \\
\text { step }\end{array}$ & $\Delta R^{2}$ & $\begin{array}{l}\beta \text { at } \\
\text { entry }\end{array}$ & $\begin{array}{l}\beta \text { at final } \\
\text { step }\end{array}$ \\
\hline Step 1 & $0.20^{\star *}$ & & & $0.18^{\star}$ & & \\
\hline Fear-avoidance beliefs & & $0.39^{*}$ & -0.04 & & $0.40^{*}$ & 0.27 \\
\hline Parent protectiveness & & 0.09 & 0.09 & & 0.05 & 0.05 \\
\hline Step 2 & 0.03 & & & 0 & & \\
\hline $\begin{array}{l}\text { Fear-avoidance } \times \\
\text { protectiveness }\end{array}$ & & & 0.47 & & & 0.14 \\
\hline Total $\mathrm{R}^{2}$ & $0.23^{\star \star}$ & & & $0.18^{\star}$ & & \\
\hline
\end{tabular}

research, which has demonstrated that pain-related cognitions (specifically pain catastrophizing) predict pain and pain-related disability (33). Additionally, our results suggest that fear-avoidance cognitions are distinct from depressive symptoms and account for more of the variance in physical activity limitations. It is important to note that the majority of the present sample did not report clinical levels of depressive symptoms. More severe depressive symptoms might play a stronger role in predicting physical activity limitations.

The support for mediation that was observed in the present sample suggests that adolescent fear-avoidance beliefs may serve as one pathway through which parental protectiveness influences adolescent activity limitations. Parental protectiveness may also impact other domains of child and adolescent cognitions and behaviours including pain catastrophizing or withdrawal from activities. It is also likely that, in addition to parental protectiveness, other psychosocial risk factors such as clinical levels of depression or anxiety symptoms, social or athletic competence, or general attitudes about physical activity might contribute to the development of fear-avoidance beliefs in adolescents. It is also possible that parental responses to pain are influenced by adolescent pain behaviours, which can serve to communicate distress and other information about current pain (34). Future longitudinal research might test other models in which the potential reciprocal influences of adolescent pain behaviours and parent pain responses are examined.

Fear and avoidance of physical activity may be important targets of cognitive and behavioural treatments for chronic pain (11). Assessment of fear-avoidance beliefs might help target treatments. For instance, adolescents with high levels of fear and avoidance may benefit most from physical therapy or exposure-based treatment approaches that emphasize returning to normal levels of physical activity participation. Interventions focusing on reducing parental protectiveness may also be useful for reducing activity limitations. Previous research has shown that parental worry is significantly associated with protective behaviours (35). Thus, interventions designed to effectively reduce worry and distress among parents of adolescents with chronic pain may also reduce protective responses to adolescent pain.

The present study had several strengths including examining fearavoidance beliefs in a mixed sample of adolescents with chronic pain and using data from multiple informants. The current study also has several limitations including the fact that the cross-sectional nature of the data does not allow us to draw conclusions about causality. Future longitudinal research is needed to assess the contribution of fearavoidance beliefs over time. Additionally, the relatively small sample size may have limited the amount of power available to detect moderation effects. In fact, the magnitude of the interaction term in the prediction of child-report activity limitations (standardized beta weight of 0.47) may have been significant in a larger sample. Thus, it is possible that with a larger sample size, adolescent fear and avoidance might have been observed to interact with parental protectiveness, similar to previous work demonstrating that child factors (specifically emotional distress such as anxiety and depression) moderated the effects of protectiveness (18). Finally, the composition of the sample was relatively 
homogeneous, consisting of female adolescents who were Caucasian; thus, results may not generalize to more diverse samples.

Additional studies are required to improve our ability to measure fear and avoidance of physical activity in children and adolescents. Existing measures initially developed for use in adults could be adapted and validated further in pediatric populations. Because fear-avoidance beliefs significantly contribute to activity limitations in the pediatric population, additional clarification of risk factors that contribute to fear-avoidance beliefs, including adolescent and parent factors, might help identify potential targets for intervention and prevention efforts. Future research should determine whether parental protectiveness might contribute to other pain-related cognitions that predict

\section{REFERENCES}

1. Jensen MP, Turner JA, Romano JM. Changes in beliefs, catastrophizing, and coping are associated with improvement in multidisciplinary pain treatment. J Consult Clin Psychol 2001;69:655-62.

2. Walker LS, Smith CA, Garber J, Claar RL. Testing a model of pain appraisal and coping in children with chronic abdominal pain. Health Psychol 2005;24:364-74.

3. Vervoort T, Eccleston C, Goubert L, Buysse A, Crombez G. Children's catastrophic thinking about their pain predicts pain and disability 6 months later. Eur J Pain 2010;14:90-6.

4. Leeuw M, Goossens ME, Linton SJ, Crombez G, Boersma K, Vlaeyen JW. The fear-avoidance model of musculoskeletal pain: Current state of scientific evidence. J Behav Med 2007;30:77-94.

5. Roelofs J, Sluiter JK, Frings-Dresen MH, et al. Fear of movement and (re)injury in chronic musculoskeletal pain: Evidence for an invariant two-factor model of the Tampa Scale for Kinesiophobia across pain diagnoses and Dutch, Swedish, and Canadian samples. Pain 2007;131:181-90.

6. Norton PJ, Asmundson GJ. Anxiety sensitivity, fear, and avoidance behavior in headache pain. Pain 2004;111:218-23.

7. Vlaeyen JW, Linton SJ. Fear-avoidance and its consequences in chronic musculoskeletal pain: A state of the art. Pain 2000;85:317-32

8. Kashikar-Zuck S, Goldschneider KR, Powers SW, Vaught MH, Hershey AD. Depression and functional disability in chronic pediatric pain. Clin J Pain 2001;17:341-9.

9. Palermo TM, Witherspoon D, Valenzuela D, Drotar D. Development and validation of the Child Activity Limitations Interview: A measure of pain-related functional impairment in school-age children and adolescents. Pain 2004;109:461-70.

10. Martin AL, McGrath PA, Brown SC, Katz J. Anxiety sensitivity, fear of pain and pain-related disability in children and adolescents with chronic pain. Pain Res Manag 2007;12:267-72.

11. Wicksell RK, Melin L, Lekander M, Olsson GL. Evaluating the effectiveness of exposure and acceptance strategies to improve functioning and quality of life in longstanding pediatric pain a randomized controlled trial. Pain 2009;141:248-57.

12. Muris P, Vlaeyen J, Meesters C. The relationship between anxiety sensitivity and fear of pain in healthy adolescents. Behav Res Ther 2001;39:1357.

13. Cardon G, de Clercq D, Geldhof E, Verstraete S, de Bourdeaudhuij I. Back education in elementary schoolchildren: The effects of adding a physical activity promotion program to a back care program. Eur Spine J 2007;16:125.

14. Swinkels-Meewisse EJ, Swinkels RA, Verbeek AL, Vlaeyen JW, Oostendorp RA. Psychometric properties of the Tampa Scale for Kinesiophobia and the Fear-Avoidance Beliefs Questionnaire in acute low back pain. Man Ther 2003;8:29-36.

15. Waddell G, Newton M, Henderson I, Somerville D, Main CJ. A Fear-Avoidance Beliefs Questionnaire (FABQ) and the role of fear-avoidance beliefs in chronic low back pain and disability. Pain 1993;52:157-68.

16. Nelson TD, Benson ER, Jensen CD. Negative attitudes toward physical activity: Measurement and role in predicting physical activity levels among preadolescents. J Pediatr Psychol 2010;35:89-98.

17. Kjonniksen L, Torsheim T, Wold B. Tracking of leisure-time physical activity during adolescence and young adulthood: A 10-year longitudinal study. Int J Behav Nutr Phys Act 2008;5:69. disability such as pain catastrophizing $(33,36)$. Additionally, future studies may investigate the usefulness of assessing fear-avoidance beliefs in clinical settings.

ACKNOWLEDGEMENTS: The authors thank the families who participated in this research, and acknowledge Sara Williams PhD, for her review of an early draft of this manuscript. This research was made possible, in part, by a Pediatric Health Pilot Project grant to the first author from the Oregon Clinical and Translational Research Institute, grant number UL1 RR024140 from the National Center for Research Resources, a component of the National Institutes of Health, and National Institutes of Health Roadmap for Medical Research.

18. Claar RL, Simons LE, Logan DE. Parental response to children's pain: The moderating impact of children's emotional distress on symptoms and disability. Pain 2008;138:172-9.

19. Chambers CT, Craig KD, Bennett SM. The impact of maternal behavior on children's pain experiences: An experimental analysis. J Pediatr Psychol 2002;27:293-301.

20. Peterson CC, Palermo TM. Parental reinforcement of recurrent pain: The moderating impact of child depression and anxiety on functional disability. J Pediatr Psychol 2004;29:331-41.

21. Walker LS, Zeman JL. Parental response to child illness behavior. J Pediatr Psychol 1992;17:49-71.

22. Walker LS, Claar RL, Garber J. Social consequences of children's pain: When do they encourage symptom maintenance? J Pediatr Psychol 2002;27:689-98.

23. Walker LS, Levy RL, Whitehead WE. Validation of a measure of protective parent responses to children's pain. Clin J Pain 2006;22:712-6.

24. Walker LS, Williams SE, Smith CA, Garber J, Van Slyke DA, Lipani TA. Parent attention versus distraction: Impact on symptom complaints by children with and without chronic functional abdominal pain. Pain 2006;122:43-52.

25. Chorpita BF, Yim L, Moffitt CA, Umemoto LA, Francis SE. Assessment of symptoms of DSM-IV anxiety and depression in children: A Revised Child Anxiety and Depression Scale. Behav Res Ther 2000;38:835-55.

26. Van Slyke DA, Walker LS. Mothers' responses to children's pain. Clin J Pain 2006;22:387-91.

27. Baron RM, Kenny DA. The moderator-mediator variable distinction in social psychological research: Conceptual, strategic, and statistical considerations. J Pers Soc Psychol 1986;51:1173-82.

28. Preacher KJ, Hayes AF. SPSS and SAS procedures for estimating indirect effects in simple mediation models. Behav Res Methods Instrum Comput 2004;36:717-31.

29. Kaczynski KJ, Claar RL, Logan DE. Testing gender as a moderator of associations between psychosocial variables and functional disability in children and adolescents with chronic pain. J Pediatr Psychol 2009;34:738-48.

30. Grotle M, Vollestad NK, Veierod MB, Brox JI. Fear-avoidance beliefs and distress in relation to disability in acute and chronic low back pain. Pain 2004;112:343-52.

31. Woby SR, Watson PJ, Roach NK, Urmston M. Adjustment to chronic low back pain - the relative influence of fear-avoidance beliefs, catastrophizing, and appraisals of control. Behav Res Ther 2004:42:761-74.

32. Crombez G, Vlaeyen JW, Heuts PH, Lysens R. Pain-related fear is more disabling than pain itself: Evidence on the role of pain-related fear in chronic back pain disability. Pain 1999;80:329-39.

33. Vervoort T, Goubert L, Eccleston C, Bijttebier P, Crombez G. Catastrophic thinking about pain is independently associated with pain severity, disability, and somatic complaints in school children and children with chronic pain. J Pediatr Psychol 2006;31:674-83.

34. Vervoort T, Goubert L, Eccleston C, et al. Expressive dimensions of pain catastrophizing: An observational study in adolescents with chronic pain. Pain 2009;146:170-6.

35. Guite JW, Logan DE, McCue R, Sherry DD, Rose JB. Parental beliefs and worries regarding adolescent chronic pain. Clin J Pain 2009;25:223-32.

36. Lynch AM, Kashikar-Zuck S, Goldschneider KR, Jones BA. Psychosocial risks for disability in children with chronic back pain. J Pain 2006;7:244-51. 


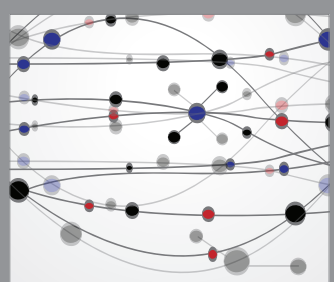

The Scientific World Journal
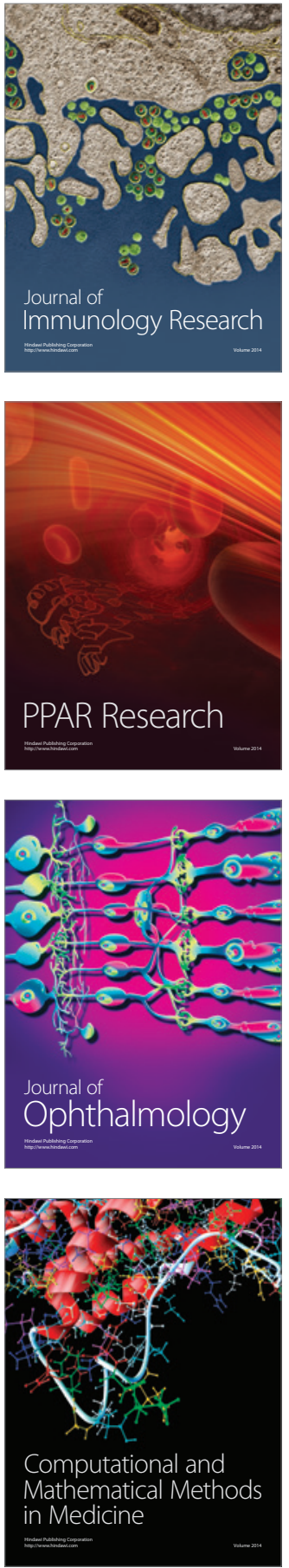

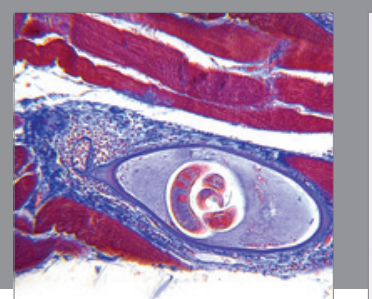

Gastroenterology Research and Practice

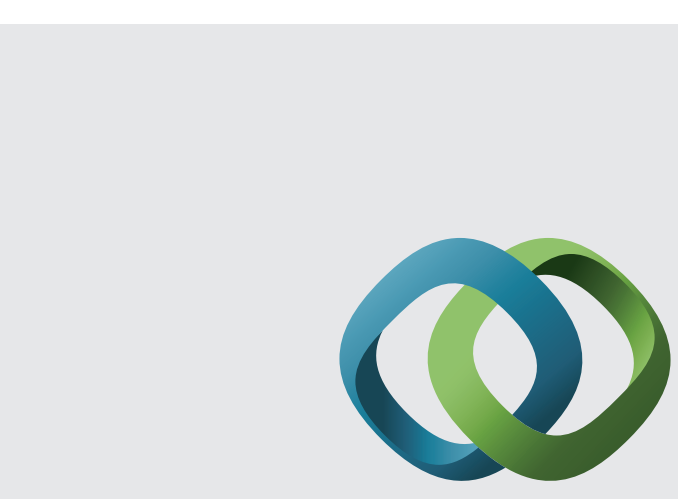

\section{Hindawi}

Submit your manuscripts at

http://www.hindawi.com
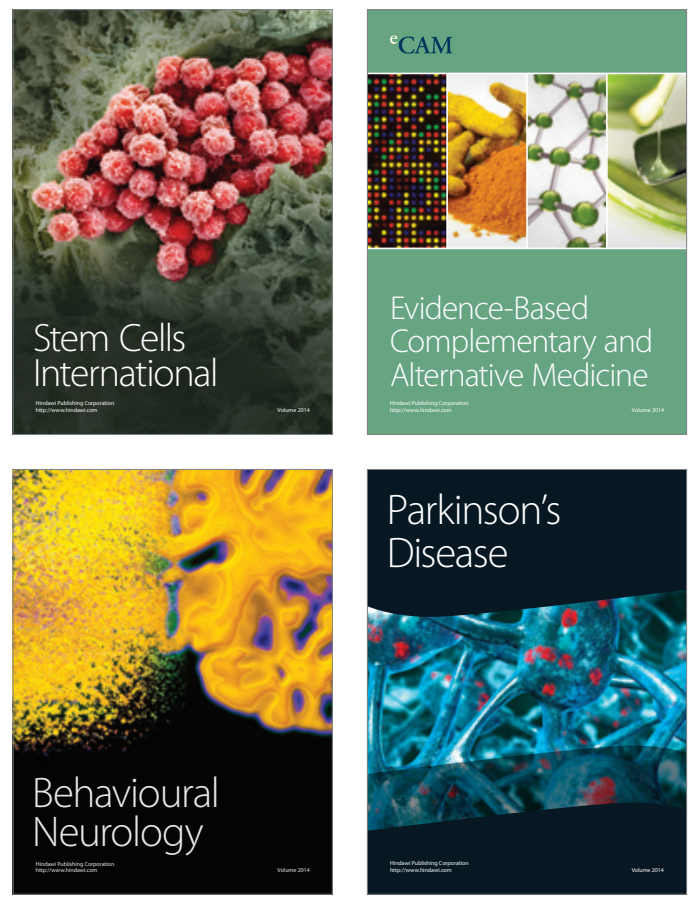
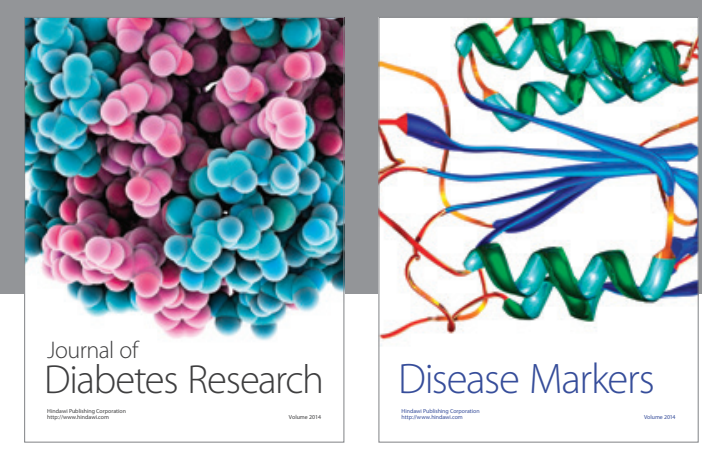

Disease Markers
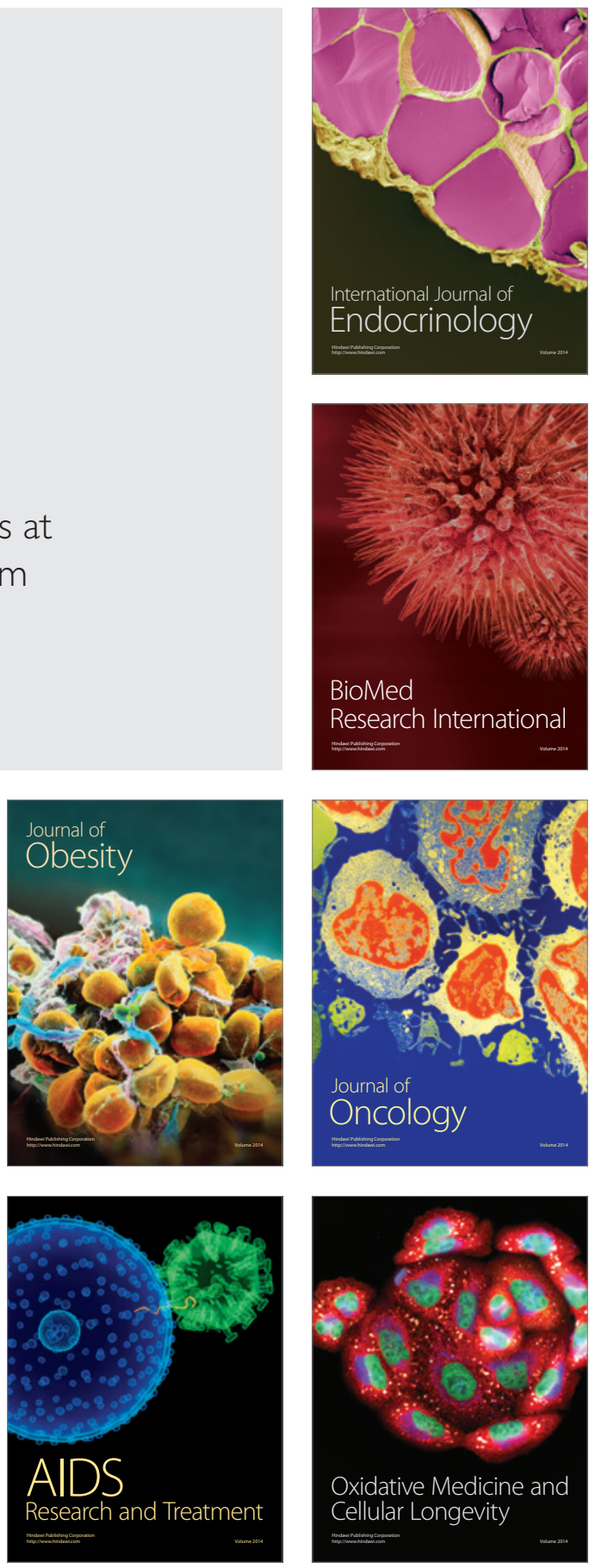